\title{
Effect of Comorbidity Assessed by the Charlson Comorbidity Index on the Length of Stay, Costs and Mortality among Older Adults Hospitalised for Acute Stroke
}

\author{
Richard Ofori-Asenso ${ }^{1,2,3}{ }^{10}$, Ella Zomer ${ }^{1}$, Ken Lee Chin ${ }^{1}, \mathrm{Si} \mathrm{Si}^{1}{ }^{1}$, Peter Markey ${ }^{4}$, Mark Tacey ${ }^{1}$, \\ Andrea J. Curtis ${ }^{3}$, Sophia Zoungas ${ }^{3}$ and Danny Liew ${ }^{1, *}$ \\ 1 Centre of Cardiovascular Research and Education in Therapeutics, Department of Epidemiology and \\ Preventive Medicine, Monash University, Melbourne, VIC 3004, Australia; \\ richard.ofori-asenso@monash.edu (R.O.-A.); ella.zomer@monash.edu (E.Z.); ken.chin@monash.edu (K.L.C.); \\ si.si@monash.edu (S.S.); mark.tacey@monash.edu (M.T.) \\ 2 Epidemiological Modelling Unit, Department of Epidemiology and Preventive Medicine, Monash \\ University, Melbourne, VIC 3004, Australia \\ 3 Division of Metabolism, Ageing and Genomics, Department of Epidemiology and Preventive Medicine, \\ Monash University, Melbourne, VIC 3004, Australia; andrea.curtis@monash.edu (A.J.C.); \\ sophia.zoungas@monash.edu (S.Z.) \\ 4 Alfred Hospital, Melbourne, VIC 3004, Australia; P.Markey@alfred.org.au \\ * Correspondence: danny.liew@monash.edu; Tel.: +61-399-030-759
}

Received: 26 September 2018; Accepted: 7 November 2018; Published: 12 November 2018

\begin{abstract}
The burden of comorbidity among stroke patients is high. The aim of this study was to examine the effect of comorbidity on the length of stay (LOS), costs, and mortality among older adults hospitalised for acute stroke. Among 776 older adults (mean age $80.1 \pm 8.3$ years; $46.7 \%$ female) hospitalised for acute stroke during July 2013 to December 2015 at a tertiary hospital in Melbourne, Australia, we collected data on LOS, costs, and discharge outcomes. Comorbidity was assessed via the Charlson Comorbidity Index (CCI), where a CCI score of $0-1$ was considered low and a CCI $\geq 2$ was high. Negative binomial regression and quantile regression were applied to examine the association between CCI and LOS and cost, respectively. Survival was evaluated with the Kaplan-Meier and Cox regression analyses. The median LOS was 1.1 days longer for patients with high CCI than for those with low CCI. In-hospital mortality rate was $18.2 \%$ (22.1\% for high CCI versus $11.8 \%$ for low CCI, $p<0.0001$ ). After controlling for confounders, high CCI was associated with longer LOS (incidence rate ratio [IRR]; 1.35, $p<0.0001$ ) and increased likelihood of in-hospital death (hazard ratio [HR]; 1.91, $p=0.003)$. The adjusted median, 25th, and 75th percentile costs were AUD $\$ 2483(26.1 \%)$, AUD $\$ 1446$ (28.1\%), and AUD $\$ 3140$ (27.9\%) higher for patients with high CCI than for those with low CCI. Among older adults hospitalised for acute stroke, higher global comorbidity (CCI $\geq 2)$ was associated adverse clinical outcomes. Measures to better manage comorbidities should be considered as part of wider strategies towards mitigating the social and economic impacts of stroke.
\end{abstract}

Keywords: stroke; cerebrovascular disease; comorbidity; cost; hospitalisation

\section{Introduction}

Non-communicable chronic diseases are prevalent among older people [1]. Data from over 60 million older adults (aged $\geq 65$ years) in 30 high-income countries showed that $88 \%$ (interquartile range [IQR] 80.8-93.2) had at least one chronic medical condition (CMC), and more than $66 \%$ had multimorbidity (i.e., the presence of two or more CMCs) [2]. 
Multimorbidity is associated with higher utilisation of healthcare services and polypharmacy and places a significant burden on the healthcare system [3]. A poor understanding of multimorbidity partly contributes to the suboptimal treatment of chronic diseases worldwide [4].

Cerebrovascular diseases, including stroke, are important causes of global morbidity and mortality. In 2013, stroke was the second most common cause of death (11.8\% of all deaths or 6.5 million deaths) and the third most common cause of disability worldwide (4.5\% of Disability-Adjusted Life Years [DALYs] from all causes) [5]. In Australia, stroke death rates declined by 70\% from 1970 to 2010 [6]. Despite this, stroke is still the third leading cause of death, being responsible for 10,869 deaths $(6.8 \%$ of all deaths) among Australians in 2015. In 2017, an estimated 475,160 people ( $2 \%$ of Australians), were living with stroke; over $70 \%$ were persons aged 65 years and over [7]. Consequently, stroke exerts a considerable economic burden [8]; the total financial cost of stroke in Australia was estimated to exceed AUD\$5 billion in 2012 [9].

Up to $90 \%$ of stroke sufferers have one or more comorbid conditions and almost a quarter have $\geq 5$ CMCs $[10,11]$. Current healthcare services are not adequately designed to cater for stroke patients with comorbidities [12]. Furthermore, the impact of comorbidities on outcomes among stroke patients is poorly understood [13]. Studies that have examined the impact of comorbidities on survival among older stroke patients are limited by small sample sizes [14-16]. Importantly, the specific impact of comorbidities on healthcare utilisation and costs among older adults hospitalised for acute stroke has not been adequately quantified within the Australian context.

The Charlson Comorbidity Index (CCI) has been demonstrated in several studies to be useful for predicting the prognosis of real-world patients with comorbidities [17,18]. Higher CCI scores are correlated with poorer functional status at discharge and an increased risk of one-year mortality in older stroke patients [19]. In the present study on older adults hospitalised for acute stroke, we sought to evaluate whether or not higher comorbidity burden, as measured by $\mathrm{CCI}$, is associated with increased length of hospital stay (LOS), hospital costs, and death rates.

\section{Materials and Methods}

\subsection{Study Design and Population}

We undertook a retrospective analysis of the records of all patients admitted for acute stroke between 1 July 2013 and 31 December 2015 to the Alfred Hospital, a large tertiary hospital with an established stroke unit in Melbourne, Victoria. Stroke was defined by the International Classification of Diseases, Version 10, Australian Modification (ICD-10-AM) codes [20], comprising intracerebral haemorrhage = I61.0, I61.1, I61.2, I61.3, I61.4, I61.5, I61.6, I61.8, I61.9, I62.9; unspecified non-traumatic intracranial haemorrhage $=$ I62.9; cerebral infarction $=$ I63.0, I63.1, I63.2, I63.3, I63.4, I63.5, I63.6, I63.8, I63.9; and undetermined stroke (not specified as haemorrhage or infarction) $=$ I64. Patients aged 65 years and over were included in the analysis if any of the above events were documented as their primary reason for admission.

\subsection{Outcomes}

The study outcomes were in-hospital death, length of stay (LOS), and hospital costs. Hospital mortality rate was defined as the ratio of deaths to the total number of admitted cases. The LOS was calculated as the period from the admission date to the date of separation (death or discharged alive). The costs of each admission were determined using the assigned Weighted Inlier Equivalent Separation (WIES) value. WIES values are used by the Victorian Government to determine casemix funding for hospitals [21]. WIES is allocated according to Diagnosis Related Group (DRG), LOS, and a number of variable co-payments. In the 2017/2018 financial year, a unit of WIES was valued at AUD\$4732 and AUD $\$ 3544$ for public and private patients, respectively. 


\subsection{Covariates}

Demographic data of interest included the patients' date of birth, sex, place of birth, usual residence, postcode of residence, marital status, and Aboriginal and Torres Strait Islander status. Postcode of residence was used to reflect quintile of socio-economic status as per the Australian Bureau of Statistics (ABS) Socio-Economic Indices for Areas (SEIFA) and the Index of Relative Socio-Economic Advantage and Disadvantage (IRSAD). Clinical data included the type of stroke, quality of care indicators (e.g., treatment carried out in a stroke unit), presence or absence of intensive care unit (ICU) stay, and complications occurred during the hospital stay.

For each patient, we calculated the CCI based on 17 comorbid conditions: congestive heart failure (weight $=1$ ), myocardial infarct (weight $=1$ ), cerebrovascular disease (weight $=1$ ), chronic pulmonary disease (weight $=1)$, paraplegia (weight $=2)$, dementia (weight $=1)$, diabetes without complications (weight $=1$ ), diabetes with complications (weight $=2$ ), cancer (weight $=2$ ), metastatic cancer ( weight $=6)$, mild liver disease (weight $=1)$, moderate or severe liver disease (weight $=3$ ), peptic ulcer disease (weight $=1$ ), peripheral vascular disease (weight $=1$ ), rheumatologic disease (weight $=1$ ), renal disease (weight $=2$ ), and human immunodeficiency virus [HIV]/acquired immune deficiency syndrome [AIDS] (weight $=6$ ) [22]. In addition, we collected data on other comorbidities such as hypertension and atrial fibrillation, which were not incorporated in the CCI calculation.

\section{Statistical Analyses}

Descriptive statistics were applied to summarise patient characteristics. Variables were compared across patients in the two CCI categories using the $\chi^{2}$ test for proportions, Student $t$-test for means, and Kruskal-Wallis rank test for the comparison of medians. Kaplan-Meier survival curves and log-rank test were used to compare in-hospital mortality between groups. A Cox proportional hazards model was then derived and adjusted for baseline clinical and sociodemographic parameters and year of admission. The test of proportional hazards assumption was performed for model calibration. In the multivariable Cox proportional hazards model, the only variable violating the proportional hazards assumption was stroke type, and therefore this was included as a stratifying factor [23]. The relationship between CCI and LOS was evaluated via a negative binomial regression (NBR) model (because of over-dispersion of the LOS data) [24], while controlling for the same list of covariates listed above. Relative LOS were described in terms of incidence-rate ratios (IRRs). Quantile regression, which permits the assessment of the effects of a covariate on all parts of the cost distribution (i.e., upper, lower, and median) rather than just the mean, as with an ordinary least squares (OLS) model [25], was used to analyse the relationship between hospital costs and CCI. An ordinary least squares (OLS) model adopting a backward stepwise approach (with variable selection cut off values of $p<0.10$ ) was used to identify predictors to be included in the quantile regression model. In all analyses, CCI was categorised as low [CCI $0-1]$ and high [CCI $\geq 2]$ [19]. Unless otherwise specified, $p$-values $<0.05$ were considered significant. All statistical analyses were performed with STATA (version 15/IC, Stata Corp, College Station, TX, USA).

\section{Ethics Approval}

The study received approval from the Alfred Hospital Human Research Ethics Committee.

\section{Results}

\subsection{Cohort Characteristics}

A total of 776 older adults was hospitalised for acute stroke between 1 July 2013 and 31 December 2015 , of whom $66.2 \%, 27.3 \%$, and $6.5 \%$ had ischaemic, haemorrhagic, and undetermined stroke, respectively. The mean age of the cohort was 80.1 ( $\mathrm{SD} \pm 8.3$ ) years and $46.7 \%$ were female. More than half $(50.4 \%)$ were married or in a de-facto relationship. Approximately $3.0 \%$ were patients from an aged care residential facility. Overall, $48.6 \%$ were born outside of Australia and $10.6 \%$ were 
non-English-speaking and required an interpreter. Less than $1 \%$ of the cohort identified themselves as Aboriginal or Torres Strait Islander. Similarly, $<1 \%$ were admitted as private patients. The percentage of the study cohort with hypertension, atrial fibrillation, congestive heart failure, metastatic cancer, renal disease, diabetes with complications, or current smokers was $65.3 \%, 24.2 \%, 6.7 \%, 3.4 \%, 10.7 \%$, $10.4 \%$, and $3.2 \%$, respectively. The mean CCI of the cohort was $2.21(\mathrm{SD} \pm 2.2)$ and the median was 2.0 (IQR 0-3). The percentage of patients with high CCI score $(\geq 2)$ was $61.9 \%$. One in ten $(10.3 \%)$ of the patients were admitted to the ICU. Table 1 summarises the patients' demographic and clinical characteristics according to low or high CCI groups. Both groups were similar in most characteristics except that the low CCI group had more haemorrhagic strokes while patients with a high CCI score experienced more complications during hospital stay.

Table 1. Sociodemographic and clinical characteristics of older adults hospitalised for acute stroke.

\begin{tabular}{|c|c|c|c|c|}
\hline \multirow{2}{*}{ Variables } & \multirow{2}{*}{ All $(n=776)$} & \multicolumn{2}{|c|}{$\mathrm{CCI} \S$} & \multirow{2}{*}{$p$-Value ${ }^{\dagger}$} \\
\hline & & Low $(n=296)$ & High $(n=480)$ & \\
\hline Mean age, years (SD) & $80.1(8.3)$ & $79.7(8.5)$ & $80.3(8.2)$ & 0.123 \\
\hline$\geq 85$ years, $n(\%)$ & $265(34.2)$ & $89(30.1)$ & $176(36.7)$ & 0.170 \\
\hline Female, $n(\%)$ & $362(46.7)$ & $144(48.7)$ & $218(45.4)$ & 0.381 \\
\hline \multicolumn{5}{|l|}{ Country of birth, $n(\%)$} \\
\hline Australia & $399(51.4)$ & $172(58.1)$ & $223(47.3)$ & \multirow{4}{*}{0.031} \\
\hline Asia & $37(4.8)$ & $11(3.7)$ & $26(5.4)$ & \\
\hline Europe & $251(32.3)$ & $82(27.7)$ & $169(35.2)$ & \\
\hline Other & $86(11.5)$ & $31(10.5)$ & $58(12.1)$ & \\
\hline Interpreter required, $n(\%)$ & $82(10.6)$ & $27(9.1)$ & $55(11.5)$ & 0.304 \\
\hline Married or in a de facto relationship, $n(\%)$ & $391(50.4)$ & $154(51.4)$ & $239(49.8)$ & 0.361 \\
\hline \multicolumn{5}{|l|}{ Type of stroke, $n(\%)$} \\
\hline Haemorrhagic & $212(27.3)$ & $102(34.4)$ & $110(22.9)$ & \multirow{3}{*}{0.001} \\
\hline Ischaemic & $514(66.2)$ & $174(58.8)$ & $340(70.8)$ & \\
\hline Undetermined & $50(6.4)$ & $20(6.8)$ & $30(6.3)$ & \\
\hline Patient with multiple records, $n(\%)$ & $34(4.4)$ & $12(4.1)$ & $22(4.6)$ & 0.726 \\
\hline \multicolumn{5}{|l|}{ Comorbidities, $n(\%)$} \\
\hline Hypertension & $507(65.3)$ & $192(64.9)$ & $315(65.6)$ & 0.829 \\
\hline Diabetes with complication & $81(10.4)$ & $0(0.0)$ & $81(16.9)$ & $<0.001$ \\
\hline Metastatic cancer & $26(3.4)$ & $0(0.0)$ & $26(5.4)$ & $<0.001$ \\
\hline Atrial fibrillation & $188(24.2)$ & $64(21.6)$ & $124(25.8)$ & 0.183 \\
\hline Renal disease & $83(10.7)$ & $0(0.0)$ & $83(17.3)$ & $<0.001$ \\
\hline Congestive heart failure & $52(6.7)$ & $5(1.7)$ & $47(9.8)$ & $<0.001$ \\
\hline Dementia & $35(4.5)$ & $13(4.4)$ & $22(4.6)$ & 0.901 \\
\hline Chronic pulmonary disease & $25(3.2)$ & $7(2.4)$ & $18(3.8)$ & 0.288 \\
\hline Myocardial infarction & $49(6.3)$ & $9(3.0)$ & $40(8.3)$ & 0.003 \\
\hline Smoking (current), $n(\%)$ & $25(3.2)$ & $9(3.0)$ & $16(3.3)$ & 0.822 \\
\hline Treated in a stroke unit, $n(\%)$ & $480(61.9)$ & $171(57.8)$ & $309(64.4)$ & 0.066 \\
\hline Admitted to ICU, $n(\%)$ & $80(10.3)$ & $29(9.8)$ & $51(10.6)$ & 0.713 \\
\hline Developed complication, $n(\%)$ & $463(59.7)$ & $147(49.7)$ & $316(65.8)$ & $<0.001$ \\
\hline Patient from aged care residential facility, $n(\%)$ & $23(3.0)$ & $6(2.0)$ & $17(3.5)$ & 0.372 \\
\hline \multicolumn{5}{|l|}{ IRSAD, $n(\%)$} \\
\hline Quintile 1 (most disadvantaged) & $163(21.0)$ & $75(25.3)$ & $88(18.4)$ & \multirow{5}{*}{0.031} \\
\hline Quintile 2 & $160(20.6)$ & $59(19.9)$ & $101(21.0)$ & \\
\hline Quintile 3 & $196(25.2)$ & $65(22.0)$ & $131(27.3)$ & \\
\hline Quintile 4 & $127(16.4)$ & $30(13.5)$ & $87(18.1)$ & \\
\hline Quintile 5 (least disadvantaged) & $130(16.8)$ & $57(19.3)$ & $73(15.2)$ & \\
\hline \multicolumn{5}{|l|}{ Admission year, $n(\%)$} \\
\hline 2013 & 187 (24.1) & $74(25.0)$ & $113(23.5)$ & \multirow{3}{*}{0.885} \\
\hline 2014 & $284(36.6)$ & $106(35.8)$ & 178 (37.1) & \\
\hline 2015 & $305(39.3)$ & $116(39.2)$ & $189(39.4)$ & \\
\hline
\end{tabular}

$n=$ number of patients; $\mathrm{SD}$ = standard deviation; $\mathrm{CCI}=$ Charlson Comorbidity Index; ICU = intensive care unit; IRSAD = Index of Relative Socio-Economic Advantage and Disadvantage; ${ }^{\dagger}$ differences between proportions were assessed via the chi-square test and means were assessed with the Student $t$-test; ${ }^{\S}$ low CCI $(0-1)$ and high CCI $(\geq 2)$. 


\subsection{Length of Stay}

Figure 1A depicts LOS among the study population. The median LOS was 5.44 (IQR 3.0-8.69) days. The unadjusted median LOS was similar among patients with ischaemic (5.67, IQR 3.33-8.75) and haemorrhagic stroke (5.63, IQR 2.85-9.08); $p$-value for difference $=0.6757$. For undetermined stroke, the median LOS was much lower (3.0, IQR 1.79-5.50). The median LOS in patients with a low CCI (0-1) was 4.81 (IQR 2.85-7.71) days compared to 5.88 (IQR 3.27-9.44) days in patients with a high $\mathrm{CCI}(\geq 2)$ ( $p$-value for difference $=<0.001)$. After adjusting for potential confounders in the NBR model, a high CCI score was associated with a 35\% higher likelihood of increased LOS compared to a low CCI score (IRR $1.35,95 \%$ CI 1.21 to $1.49 ; p<0.001$ ).

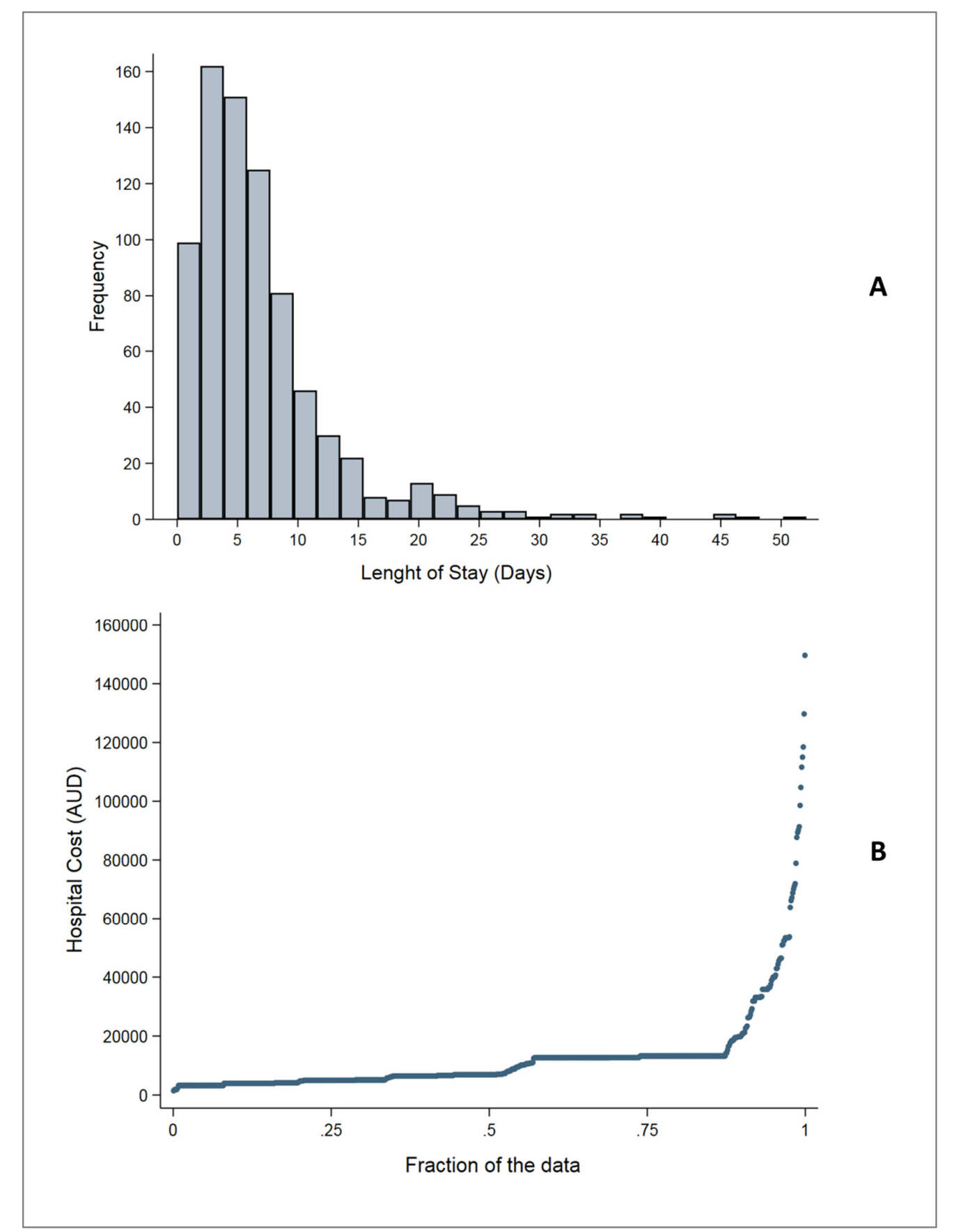

Figure 1. (A) Histogram depicting the distribution of LOS; and (B) quantile distribution of hospital costs among the study population of older adults hospitalised for acute stroke. 


\subsection{Costs}

The hospital cost among the cohort varied widely from AUD $\$ 1470$ to $\$ 149,637$. Figure 1B illustrates the quantile distribution of direct hospital costs incurred by the study cohort. The overall unadjusted median hospital cost among the cohort was AUD\$6924 (IQR \$4971-\$13,238). The unadjusted median cost among patients with ischaemic stroke was AUD $\$ 7022$ (IQR \$5112-\$13,237) and that among those with haemorrhagic stroke was AUD\$8026 (IQR \$4139-\$13,238); $p$-value for difference $=0.8155$. The unadjusted median cost among patients with undetermined stroke was much lower (AUD\$5112, IQR \$3943-\$7032). Patients with a low CCI score (0-1) incurred lower median unadjusted hospital costs (AUD\$6447; IQR \$4971-\$12,658) compared to those with a high CCI score $(\geq 2)$ (AUD \$12,658; IQR \$5536-\$13,238) ( $p=0.0001)$. When adjusted for potential confounders (sex, separation status (died or discharged alive), ICU stay, and treatment within stroke unit), the median hospital cost was AUD\$2481 (26.1\%), and 25th and 75th percentile costs were AUD\$1446 (28.1\%) and AUD $\$ 3140(27.9 \%)$, respectively, which was higher in the high CCI $(\geq 2)$ group compared to the low CCI group (Table 2, models 1, 2, and 3).

Table 2. Regression models of adjusted median and percentile costs associated with hospitalised cases of acute stroke.

\begin{tabular}{ccccccc}
\hline & \multicolumn{2}{c}{ Model 1 $^{\text {a }}$ : 25th Percentile } & \multicolumn{2}{c}{ Model 2 ${ }^{\text {a }}$ : Median } & \multicolumn{2}{c}{ Model 3 $^{\text {a }}$ : 75th Percentile } \\
\hline & Estimate & $\mathbf{9 5 \% ~ C I ~}$ & Estimate & $\mathbf{9 5 \% ~ C I ~}$ & Estimate & $\mathbf{9 5 \% ~ C I ~}$ \\
\hline $\begin{array}{c}\text { High CCI }(\geq 2) \\
\text { Constant }\end{array}$ & 1446 & $832-2060^{* *}$ & 2483 & $788-4175^{* *}$ & 3140 & $1214-5068^{* *}$ \\
\hline
\end{tabular}

a Adjusted for sex, separation status (i.e., died or discharged alive), intensive care unit stay, and treatment within stroke unit; ${ }^{* *}$ statistically significant at $p<0.01$.

\subsection{Mortality}

Overall, in-hospital death occurred in $18.2 \%$ of the study cohort. The unadjusted in-hospital mortality rate varied by stroke sub-type: $12.7 \%$ in patients with ischaemic stroke and $30.2 \%$ in those with haemorrhagic stroke ( $p$-value for differences $=<0.001)$. The unadjusted proportion of patients with undetermined stroke who died was $24.0 \%$. The proportions of patients with a low CCI score $(0-1)$ and a high CCI score $(\geq 2)$ who died were $11.8 \%$ and $22.1 \%$, respectively ( $p$-value for difference in unadjusted proportions $=<0.0001$ ).

Patients with low CCI scores had better survival rates compared to patients with high CCI scores ( $p$-value for rank test $=0.0265)$ (Figure 2$)$. A high CCI score $(\geq 2)$ was associated with nearly two times greater likelihood of death than a low CCI score (0-1) (hazard ratio [HR]; 1.91, 95\% CI 1.25-2.90, $p=0.003$ ) after adjusting for key clinical and sociodemographic confounders as listed in Table 1. 


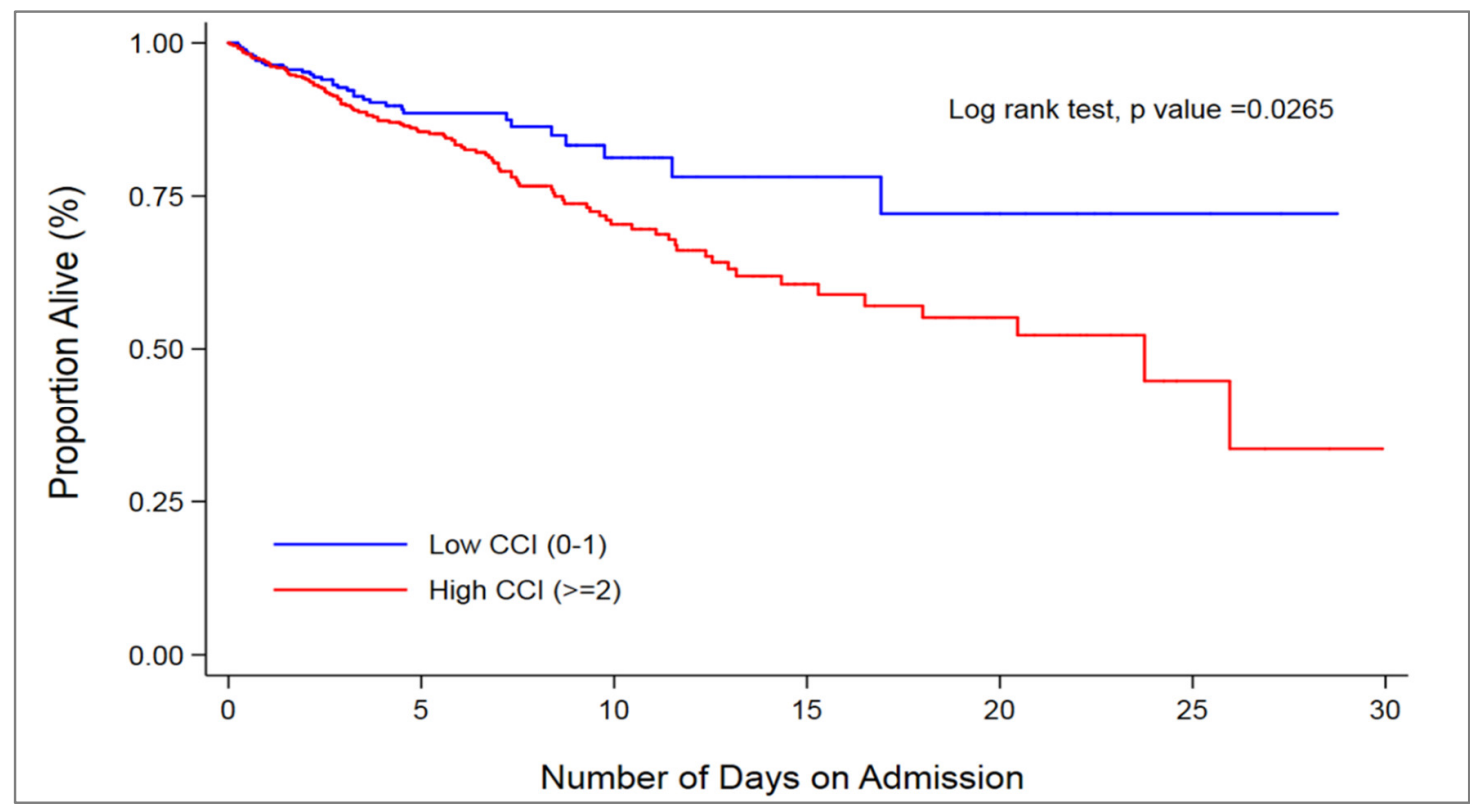

Figure 2. Unadjusted Kaplan-Meier survival curves for patients admitted for acute stroke stratified by Charlson Comorbidity Index (CCI) categories.

\section{Discussion}

In the present study, we found that a high CCI score was associated with increased LOS, higher hospital costs, and a greater likelihood of in-hospital death. Specifically, patients with a high CCI score $(\geq 2)$ had a 1.1 day longer LOS ( $35 \%$ increased risk) compared to those with a low CCI score $(0-1)$. The adjusted median hospital cost for patients with high CCI was 26.1\% (AUD\$2481) higher than for patients with low CCI. A high CCI score was also associated with $91 \%$ increased risk of death compared to a low CCI score.

Few studies have examined the relationship between comorbidities and LOS, mortality, and, in particular, healthcare costs among older adults hospitalised for acute stroke. Our study highlighted the substantive clinical and economic impact of comorbidities among a diverse population of older adults from a developed country with a universal healthcare system.

Globally, older adults have a higher risk of stroke mortality than younger individuals [26-29]. Grube and colleagues reported that persons aged $\geq 85$ years were more likely to die after stroke compared with those aged <65 years (odds ratio [OR]; 13.50, 95\% CI; 5.54-32.89) [26]. In our study, almost one in five $(18.2 \%)$ of the cohort experienced in-hospital death, which was higher compared to that reported among cohorts of older adults in Italy (10.9\%) [14], China (3.1\%) [30], Saudi Arabia $(11.0 \%)$ [31], and Canada (13.4\%) [32], although a recent study reported a much higher $(35.7 \%)$ in-hospital stroke death rate in Turkey [33]. The differences were likely to be due to a myriad of factors, including study design, disease definition, local factors (e.g., the standard of hospital care or treatment received), but particularly due to the fact that, in the other studies, all patients had ischaemic stroke, for which the case fatality was significantly lower than for haemorrhagic stroke [34]. Among our cohort, the unadjusted death rates among those with haemorrhagic stroke was over two times higher than those with ischaemic stroke. Our study population was also older than the populations from the other studies. Furthermore, the differences could be attributed to acuity and accuracy of admission diagnoses for stroke in Australia or issues with classification. For example, in areas with less experience of using ICD coding, some transient ischaemic attacks (TIAs) with better outcomes could be misclassified as stroke [35].

The ageing process, as represented by chronically elevated pro-inflammatory markers, is a leading risk factor for major CMCs such as cardiovascular diseases, dementia, and chronic kidney disease [1]. The CCI is reflective of the cumulative burden of disease. We found that CCI was strongly associated 
with in-hospital death among hospitalised acute stroke patients, supporting the use of CCI as a tool in predicting in-hospital death among this population $[17,36]$. CCI has been consistently shown to independently predict death among patients with sepsis [37], congestive heart failure, and cancer [38].

Our results also indicate that CCI is associated with longer LOS and higher hospitalisation costs in Australia. CCI has previously been found to predict LOS in stroke patients [39], as well as in patients with cancer [38], sepsis, or those undergoing surgical procedures [40]. Among patients hospitalised for hip fracture in the USA, Johnson and colleagues [41], observed that patients with a CCI score of 2 , on average, stayed 1.92 extra days in the hospital and incurred USD $\$ 8698$ extra costs compared to those with a CCI score of 0 .

The relationship between the CCI score and multiple outcomes (cost, LOS, and mortality) as observed in this study supports the notion that CCI can be adapted for risk stratification, particularly when negotiating bundled payments [41,42], as it embodies a good representation of the complexity and current state of the patient [14]. For clinicians working within acute care settings, CCI could be employed to identify patients most likely to experience worse outcomes for whom greater monitoring may be required. Given the clinical and economic impact of comorbidities among older adults with acute stroke, measures to manage comorbidities are important and should be considered as part of the wider strategies aimed at reducing the social and economic impacts of stroke. For example, systematic evaluation and screening of comorbidities may allow for earlier identification of patients at risk and targeting of in-hospital management. Improved care coordination, inter-disciplinary transition of care, and management counselling during hospitalisation are all important strategies that could contribute to the optimised management of comorbidities [3,43].

There were several limitations to our study that warrant mention. First, we analysed only administrative hospital data that were not collected for research purposes. The data may be subject to coding errors or omissions and inaccurate classification of diagnoses and complications. Secondly, information was not available for important covariates such as body mass index (BMI), disease severity, and laboratory and imaging results. Thirdly, given that our sample population was selected from a single hospital, selection bias may limit the generalisability of our findings. Fourthly, the CCI did not account for the effects of gradations of disease progression and severity. Furthermore, because of the differences in our study population and that from which the original CCI was developed, the performance of the CCI as a prognostic variable might not be the same [44]. Finally, the use of in-hospital data meant that we were unable to examine the impact of CCI on longer-term post-discharge outcomes.

\section{Conclusions}

Among older adults hospitalised for acute stroke, high global comorbidity (CCI $\geq 2)$ was associated with increased LOS, costs, and mortality. The adaptation of CCI within acute care settings has the potential to offer a rapid and reliable approach to identifying patients likely to experience adverse outcomes who may benefit from closer monitoring. Measures to address comorbidities need to be considered as part of wider strategies for reducing the social and economic impact of stroke.

Author Contributions: R.O.-A., D.L., and E.Z. conceived the study. R.O.-A., D.L., E.Z., and P.M. acquired data. R.O.-A. analysed the data, interpreted results, and drafted the manuscript. All other authors interpreted data and provided critical revision of the manuscript. The final version to be submitted was approved by all the authors.

Funding: Richard Ofori-Asenso is supported by a Monash Graduate Scholarship and Monash International Postgraduate Research Scholarship for his doctoral studies. Sophia Zoungas is funded by a National Health and Medical Research Council Senior Research Fellowship. No other funding has been required to undertake this work.

Conflicts of Interest: Sophia Zoungas reports past participation in advisory boards and/or receiving honoraria from AstraZeneca/Bristol-Myers Squibb Australia; Janssen-Cilag; Merck, Sharp, and Dohme (Australia); Novartis Australia; Novo Nordisk; Sanofi and Servier Laboratories for work unrelated to this study. Danny Liew reports past participation in advisory boards and/or receiving honoraria from Abbvie, Astellas, AstraZeneca, Bristol-Myers Squibb, Novartis, Pfizer, Sanofi and Shire for work unrelated to this study. 


\section{References}

1. Kennedy, B.K.; Berger, S.L.; Brunet, A.; Campisi, J.; Cuervo, A.M.; Epel, E.S.; Franceschi, C.; Lithgow, G.J.; Morimoto, R.I.; Pessin, J.E.; et al. Geroscience: Linking aging to chronic disease. Cell 2014, 159, 709-713. [CrossRef] [PubMed]

2. Ofori-Asenso, R.; Chin, K.L.; Curtis, A.J.; Zomer, E.; Zoungas, S.; Liew, D. Recent Patterns of Multimorbidity Among Older Adults in High-Income Countries. Popul. Health Manag. 2018. [CrossRef] [PubMed]

3. Barnett, K.; Mercer, S.W.; Norbury, M.; Watt, G.; Wyke, S.; Guthrie, B. Epidemiology of multimorbidity and implications for health care, research, and medical education: A cross-sectional study. Lancet 2012, 380, 37-43. [CrossRef]

4. Wallace, E.; Salisbury, C.; Guthrie, B.; Lewis, C.; Fahey, T.; Smith, S.M. Managing patients with multimorbidity in primary care. BMJ 2015, 350, h176. [CrossRef] [PubMed]

5. Feigin, V.L.; Norrving, B.; Mensah, G.A. Global Burden of Stroke. Circ. Res. 2017, 120, 439-448. [CrossRef] [PubMed]

6. Australian Institute of Health and Welfare. Stroke and Its Management in Australia: An Update; Cardiovascular Disease Series No. 37. Cat. No. CVD 61; AIHW: Canberra, Australia, 2013.

7. Stroke Foundation. No Postcode Untouched: Stroke in Australia 2017. Available online: https:// strokefoundation.org.au/What-we-do/Research/No-postcode-untouched (accessed on 13 May 2018).

8. Phillips, M.C.; Leyden, J.M.; Chong, W.K.; Kleinig, T.; Czapran, P.; Lee, A.; Koblar, S.A.; Jannes, J. Ischaemic stroke among young people aged 15 to 50 years in Adelaide, South Australia. Med. J. Aust. 2011, 195, 610-614. [CrossRef] [PubMed]

9. Deloitte Access Economics. The Economic Impact of Stroke in Australia: Scoping Cost Effective Prevention. Available online: https://www2.deloitte.com/au/en/pages/economics/articles/economic-impact-strokeaustralia.html (accessed on 13 May 2018).

10. Gallacher, K.I.; Batty, G.D.; McLean, G.; Mercer, S.W.; Guthrie, B.; May, C.R.; Langhorne, P.; Mair, F.S. Stroke, multimorbidity and polypharmacy in a nationally representative sample of 1,424,378 patients in Scotland: Implications for treatment burden. BMC Med. 2014, 12, 151. [CrossRef] [PubMed]

11. Tran, J.; Norton, R.; Conrad, N.; Rahimian, F.; Canoy, D.; Nazarzadeh, M.; Rahimi, K. Patterns and temporal trends of comorbidity among adult patients with incident cardiovascular disease in the UK between 2000 and 2014: A population-based cohort study. PLoS Med. 2018, 15, e1002513. [CrossRef] [PubMed]

12. Hill, M.D.; Kamal, N.; Jeerakathil, T. Bridging the Evidence-to-Practice Gap in Stroke Care. JAMA 2018. [CrossRef] [PubMed]

13. Gallacher, K.; Morrison, D.; Jani, B.; Macdonald, S.; May, C.R.; Montori, V.M.; Erwin, P.J.; Batty, G.D.; Eton, D.T.; Langhorne, P.; et al. Uncovering treatment burden as a key concept for stroke care: A systematic review of qualitative research. PLoS Med. 2013, 10, e1001473. [CrossRef] [PubMed]

14. Falsetti, L.; Viticchi, G.; Tarquinio, N.; Silvestrini, M.; Capeci, W.; Catozzo, V.; Fioranelli, A.; Buratti, L.; Pellegrini, F. Charlson comorbidity index as a predictor of in-hospital death in acute ischemic stroke among very old patients: A single-cohort perspective study. Neurol. Sci. 2016, 37, 1443-1448. [CrossRef] [PubMed]

15. Pettinari, L.; Capeci, W.; Falsetti, L.; Tarquinio, N.; Kafyeke, A.; Fioranelli, A.; Catozzo, V.; Viticchi, G.; Gentile, A.; Pellegrini, F. Prevalence of the most common comorbidities in a cohort of elderly patients affected by acute ischemic stroke. Ital. J. Med. 2015, 9, 80. [CrossRef]

16. Caballero, P.E.J.; Espuela, F.L.; Cuenca, J.C.P.; Moreno, J.M.R.; Zamorano, J.D.P.; Naranjo, I.C. Charlson Comorbidity Index in Ischemic Stroke and Intracerebral Hemorrhage as Predictor of Mortality and Functional Outcome after 6 Months. J. Stroke Cerebrovasc. Dis. 2013, 22, E214-E218. [CrossRef] [PubMed]

17. Rashid, M.; Kwok, C.S.; Gale, C.P.; Doherty, P.; Olier, I.; Sperrin, M.; Kontopantelis, E.; Peat, G.; Mamas, M.A. Impact of co-morbid burden on mortality in patients with coronary heart disease, heart failure, and cerebrovascular accident: A systematic review and meta-analysis. Eur. Heart J. Qual. Care Clin. Outcomes 2017, 3, 20-36. [CrossRef] [PubMed]

18. Yurkovich, M.; Avina-Zubieta, J.A.; Thomas, J.; Gorenchtein, M.; Lacaille, D. A systematic review identifies valid comorbidity indices derived from administrative health data. J. Clin. Epidemiol. 2015, 68, 3-14. [CrossRef] [PubMed]

19. Goldstein, L.B.; Samsa, G.P.; Matchar, D.B.; Horner, R.D. Charlson Index comorbidity adjustment for ischemic stroke outcome studies. Stroke 2004, 35, 1941-1945. [CrossRef] [PubMed] 
20. Australian Consortium for Classification Development. ICD-10-AM/ACHI/ACS. Available online: https: / / www.accd.net.au/Icd10.aspx (accessed on 14 May 2018).

21. Victoria State Government. Casemix Funding. Available online: https://www2.health.vic.gov.au/hospitalsand-health-services / funding-performance-accountability/activity-based-funding/casemix-funding (accessed on 11 July 2018).

22. Quan, H.; Sundararajan, V.; Halfon, P.; Fong, A.; Burnand, B.; Luthi, J.C.; Saunders, L.D.; Beck, C.A.; Feasby, T.E.; Ghali, W.A. Coding algorithms for defining comorbidities in ICD-9-CM and ICD-10 administrative data. Med. Care 2005, 43, 1130-1139. [CrossRef] [PubMed]

23. Bradburn, M.J.; Clark, T.G.; Love, S.B.; Altman, D.G. Survival analysis part II: Multivariate data analysis-An introduction to concepts and methods. Br. J. Cancer 2003, 89, 431-436. [CrossRef] [PubMed]

24. Yang, Y.; Thumboo, J.; Earnest, A.; Yong, S.L.; Fong, K.Y. The effect of comorbidity on hospital mortality in patients with SLE from an Asian tertiary hospital. Lupus 2014, 23, 714-720. [CrossRef] [PubMed]

25. Beyerlein, A. Quantile regression-opportunities and challenges from a user's perspective. Am. J. Epidemiol. 2014, 180, 330-331. [CrossRef] [PubMed]

26. Grube, M.M.; Koennecke, H.C.; Walter, G.; Meisel, A.; Sobesky, J.; Nolte, C.H.; Wellwood, I.; Heuschmann, P.U.; Berlin Stroke, R. Influence of acute complications on outcome 3 months after ischemic stroke. PLoS ONE 2013, 8, e75719. [CrossRef] [PubMed]

27. Smith, E.E.; Shobha, N.; Dai, D.; Olson, D.M.; Reeves, M.J.; Saver, J.L.; Hernandez, A.F.; Peterson, E.D.; Fonarow, G.C.; Schwamm, L.H. Risk score for in-hospital ischemic stroke mortality derived and validated within the Get With the Guidelines-Stroke Program. Circulation 2010, 122, 1496-1504. [CrossRef] [PubMed]

28. Ovbiagele, B. Nationwide trends in in-hospital mortality among patients with stroke. Stroke 2010, 41, 1748-1754. [CrossRef] [PubMed]

29. Cadilhac, D.A.; Kilkenny, M.F.; Levi, C.R.; Lannin, N.A.; Thrift, A.G.; Kim, J.; Grabsch, B.; Churilov, L.; Dewey, H.M.; Hill, K.; et al. Risk-adjusted hospital mortality rates for stroke: Evidence from the Australian Stroke Clinical Registry (AuSCR). Med. J. Aust. 2017, 206, 345-350. [CrossRef] [PubMed]

30. Ong, C.T.; Sung, S.F.; Wong, Y.S.; Wu, C.S.; Hsu, Y.C.; Su, Y.H.; Li, C.H.; Hung, L.C. Risk Factors for In-Hospital Mortality among Ischemic Stroke Patients in Southern Taiwan. Int. J. Gerontol. 2016, 10, 86-90. [CrossRef]

31. Alhazzani, A.A.; Mahfouz, A.A.; Abolyazid, A.Y.; Awadalla, N.J.; Katramiz, K.; Faraheen, A.; Khalil, S.N.; Aftab, R. In Hospital Stroke Mortality: Rates and Determinants in Southwestern Saudi Arabia. Int. J. Environ. Res. Public Health 2018, 15. [CrossRef] [PubMed]

32. Saposnik, G.; Cote, R.; Phillips, S.; Gubitz, G.; Bayer, N.; Minuk, J.; Black, S. Stroke outcome in those over 80: A multicenter cohort study across Canada. Stroke 2008, 39, 2310-2317. [CrossRef] [PubMed]

33. Dogan, N.O.; Akinci, E.; Gumus, H.; Akilli, N.B.; Aksel, G. Predictors of Inhospital Mortality in Geriatric Patients Presenting to the Emergency Department With Ischemic Stroke. Clin. Appl. Thromb./Hemost. Off. J. Int. Acad. Clin. Appl. Thromb./Hemost. 2016, 22, 280-284. [CrossRef] [PubMed]

34. Andersen, K.K.; Olsen, T.S.; Dehlendorff, C.; Kammersgaard, L.P. Hemorrhagic and ischemic strokes compared: Stroke severity, mortality, and risk factors. Stroke 2009, 40, 2068-2072. [CrossRef] [PubMed]

35. Kokotailo, R.A.; Hill, M.D. Coding of stroke and stroke risk factors using international classification of diseases, revisions 9 and 10. Stroke 2005, 36, 1776-1781. [CrossRef] [PubMed]

36. Ng, A.C.; Chow, V.; Yong, A.S.; Chung, T.; Kritharides, L. Prognostic impact of the Charlson comorbidity index on mortality following acute pulmonary embolism. Respiration 2013, 85, 408-416. [CrossRef] [PubMed]

37. Yang, Y.; Yang, K.S.; Hsann, Y.M.; Lim, V.; Ong, B.C. The effect of comorbidity and age on hospital mortality and length of stay in patients with sepsis. J. Crit. Care 2010, 25, 398-405. [CrossRef] [PubMed]

38. Albertsen, P.C.; Moore, D.F.; Shih, W.; Lin, Y.; Li, H.; Lu-Yao, G.L. Impact of comorbidity on survival among men with localized prostate cancer. J. Clin. Oncol. Off. J. Am. Soc. Clin. Oncol. 2011, 29, 1335-1341. [CrossRef] [PubMed]

39. Lim, J.H.; Cheon, S.H. Analysis of variation in length of stay (LOS) after ischemic and hemorrhagic stroke using the Charlson Comorbidity Index (CCI). J. Phys. Ther. Sci. 2015, 27, 799-803. [CrossRef] [PubMed]

40. Lakomkin, N.; Kothari, P.; Dodd, A.C.; VanHouten, J.P.; Yarlagadda, M.; Collinge, C.A.; Obremskey, W.T.; Sethi, M.K. Higher Charlson Comorbidity Index Scores Are Associated With Increased Hospital Length of Stay After Lower Extremity Orthopaedic Trauma. J. Orthop. Trauma 2017, 31, 21-26. [CrossRef] [PubMed] 
41. Johnson, D.J.; Greenberg, S.E.; Sathiyakumar, V.; Thakore, R.; Ehrenfeld, J.M.; Obremskey, W.T.; Sethi, M.K. Relationship between the Charlson Comorbidity Index and cost of treating hip fractures: Implications for bundled payment. J. Orthop. Traumatol. Off. J. Ital. Soc. Orthop. Traumatol. 2015, 16, 209-213. [CrossRef] [PubMed]

42. Kaatz, S.; Coleman, C.I.; Bookhart, B.; Laliberte, F.; Nelson, W.W.; Brown, K.; Martin, S.; Schein, J.; Lefebvre, P. Implications of stroke and bleeding risk scores and comorbidities on episode-based bundled payments for patients with nonvalvular atrial fibrillation. Curr. Med. Res. Opin. 2018, 34, 275-284. [CrossRef] [PubMed]

43. Rudin, R.S.; Gidengil, C.A.; Predmore, Z.; Schneider, E.C.; Sorace, J.; Hornstein, R. Identifying and Coordinating Care for Complex Patients: Findings from the Leading Edge of Analytics and Health Information Technology. Rand Health Q. 2017, 6, 2. [PubMed]

44. Austin, S.R.; Wong, Y.N.; Uzzo, R.G.; Beck, J.R.; Egleston, B.L. Why Summary Comorbidity Measures Such As the Charlson Comorbidity Index and Elixhauser Score Work. Med. Care 2015, 53, e65-e72. [CrossRef] [PubMed]

(C) 2018 by the authors. Licensee MDPI, Basel, Switzerland. This article is an open access article distributed under the terms and conditions of the Creative Commons Attribution (CC BY) license (http:/ / creativecommons.org/licenses/by/4.0/). 